\title{
DIMENSÃO SOCIAL DO MEIO AMBIENTE
}

\section{Avançar no tratamento de problemáticas relativas ao Meio Ambiente requer tratar o tema em suas múltiplas interações sócio-econômicas}

A Educação Ambiental faz parte do conjunto de ações que definem o projeto político para o Brasil e, portanto, depende de decisões centrais. Os trabalhos sobre o meio ambiente, embora venham de longa data - recentemente chamados de Educação Ambiental -, sempre estiveram restritos a esforços de pequenos grupos e foram desenvolvidos de forma fragmentada, tanto em ambientes acadêmicos quanto em nível de iniciativas chamadas ambientalistas.

Colaborar com uma proposta que está em curso neste momento ${ }^{1}$, significa não deixar de reconhecer aspectos históricos da questão do ambiente, da educação e da saúde. Estes aspectos terão importância fundamental na definição dos critérios que qualificarão a consistência do processo de Educação Ambiental a ser estabelecido com a sustentação política exigida.

Há algumas ideías pré-estabelecidas com relação à Educação Ambiental que, de certa forma, impedem a organização de programas. Uma delas é considerar apenas a dimensão biológica do ambiente, esquecendo ou não considerando a dimensão social as realações sociais, culturais, políticas, econômicas - e a dimensão da subjetividade humana. A existência desses três registros evidencia claramente o caráter interdisciplinar da educação ambiental. A interdiscipli- naridade é exigência metodológica do próprio objeto de estudo - o ambiente ${ }^{2}$.

Também é preciso ultrapassar uma situação dispersiva, e ir em direção a uma atuação coletiva organizada, pois um dos impedimentos para a compreensão da amplitude do tema, no espaço da escola, é o fato de não se organizar o conhecimento no formato que está sendo exigido.

\section{OS AUTORES}

\section{Célia P. de Carvalho}

Professora Doutora do Departamento de Psicologia e Educação e do Laboratório de Ensino de Ciências da Faculdade de Filosofia, Ciências e Letras de Ribeirão Preto da USP.

\section{Heloísa Bettiol}

Professora Doutora do Departamento de Puericultura da Faculdade de Medicina de Ribeirão Preto da USP.

\section{Marco A. Barbieri}

Professor Doutor do Departamento de Puericultura da Faculdade de Medicina de Ribeirão Preto da USP.

\section{Marisa Ramos Barbieri}

Professora Doutora do Departamento de Psicologia e Educação e do Laboratório de Ensino de Ciências da Faculdade de Filosofia, Ciências e Letras de Ribeirão Preto da USP.

1. SCHALL, V.T., et al. Educação, Saúde e Meio Ambiente, Desenvolvimento e Saúde. In: Carta da Saúde, Agenda Sanitária. Conferência Internacional do Meio Ambiente, Desenvolvimento e Saúde-CIMADES, Rio de Janeiro: FIOCRUZ, 1992 , p.25-9.

2. GUATTARI, Félix. As três ecologias. Campinas: Papirus, 1990. 
Outro impedimento é a ausência de questionamento, de maneira regular e sistematiza$\mathrm{da}$, nos programas existentes de formação e atualização de profissionais.

Há um locus intermediário a ser criado entre as produções, planos, projetos e as execuções, práticas profissionais propriamente ditas. No que se refere à Saúde e à Educação, é possível identificar um vazio entre as instituições formadoras de pessoal, as quais são também produtoras de conhecimento e de normas, além de serem o local onde se dão as chamadas práticas de saúde e de educação.

A proposta é que se organizem grupos com especialistas com o objetivo de assessorar metodologicamente a formação dos profissionais em Educação Ambiental, no próprio local de trabalho (escolas, unidades de saúde), a partir de projetos e da prática de investigação. É fundamental que se propicie o encontro dos profissionais, criando condições de atividade permanente cuja construção depende de estudos investigativos, exercício de idéias e trabalho em grupo ${ }^{3}$.

Tanto a produção do conhecimento quanto a formação de profissionais interessam na reorganização do campo de trabalho em direção à definição de um novo "paradigma" relacionado e sintonizado com Educação Ambiental. É essa a percepção do grupo que vem se organizando para relacionar estudos da criança e do adolescente, tendo a escola como local de referência ${ }^{4}$. Se a Saúde passa a ser um conhecimento transmitido na escola, tendo como pano de fundo a Educação Ambiental, então a Saúde passa a ter um espaço garantido.
Como ficam as disciplinas como Português, Matemática, História, Geografia, Ciências, Biologia e outras? Há mais de meio século vêm sendo estruturados os programas das disciplinas e o diploma dos professores que os coordenam.

Se a Educação Ambiental é uma área de estudos, de investigação de conhecimento e, ao mesmo tempo, é uma prática, ela exige o pressuposto interdisciplinar, o que a impossibilita de ser disciplina em qualquer grau de ensino.

Interessa a todas as áreas do saber. Não se pode prescindir de nenhuma para a organização de programas e disciplinas que atendam à educação formal e à informal, especialmente a relação entre elas. Alguns estudos, nessa direção, foram feitos e podem acelerar a organização de programas e currículos 5 .

\section{MEIO AMBIENTE E ORGANIZAÇÃO SOCIAL}

É importante ressaltar que, no Brasil, a preocupação com a questão ambiental foi se constituindo principalmente nos anos 70 , no contexto da ditadura militar, para tentar atrair capitais e investimentos estrangeiros. O Estado então se curvou à pressão da preocupação ecológica que desde os anos 50 crescia em nível internacional, levando as instituições financeiras a colocarem exigências para a adoção de investimentos.

3. BARBIERI, Marisa Ramos; CARVALHO, Célia P. O LEC - estratégias e procedimentos. In: A Universidade e o aprendizado escolar de Ciências. Formação de professores de Ciências, Projeto USP/BID (org. USP/CECAE), 1993, p.143-6.

4. BARBIERI, Marisa Ramos, et al. Nucleus for the study of children and adolecents. Resumés des Communications. Biennale de L'éducation et de la formation, Paris: 36, 1994.

5. REIGOTA, M. Meio Ambiente e Representação Social. São Paulo: Cortez, 1995. SANTOS, L.M.S. et al. Educação e Saúde: desafios, impasses e perspectivas no ensino fundamental e habilitação específica para o magistério. Monografia apresentada como conclusão do Curso de Aperfeiçoamento "Espaço Interdisciplinar para o Ensino das Ciências", LEC/FFCLRP-USP. 
Foram criados diversos órgãos para gerir o meio ambiente, antes mesmo que se enraizasse no país um movimento ecológico. Aceitaram-se exigências para fechar acordos financeiros, que em geral nunca foram cumpridas.

A falta de memória e o silêncio histórico a respeito de momentos significativos para a formação da consciência ecológica foram contribuindo para um grave viés: a defesa do "verde" chegou antes da cidadania.

Grupos se organizam mais fácil e prontamente para se opor ao corte de árvores, ao desmatamento, à extinção de animais, à poluição causada por indústrias, mas é muito mais lento o movimento para perceber outros registros ecológicos, como os políticos, os das relações sociais, o da subjetividade. Exemplo dessa antecipação é o Estatuto da Criança e do Adolescente, aprovado no final dos anos 80 , início dos 90. O Estado, para responder à crítica ambiental, de origem internacional, de descuido com a infância, cria o Estatuto da Criança e do Adolescente antes que a população esteja organizada para entendêlo e, então, atender às obrigações e aos direitos deles decorrentes. Conseqüentemente, surgem dificuldades concretas para hospitais e outras unidades de saúde - como a relação entre o direito que a criança tem de ser acompanhada durante o tratamento médico-hospitalar e a falta de infraestrutura material e funcional para atender mãe e crianças juntas.

Outro exemplo de atitudes que de certa forma impedem ou dificultam a com- preensão da questão ambiental na sua complexidade é o raciocínio "lógico dualista" que estabelece uma única razão ou causa para os fenômenos. Assim, ao explicar a relação desnutrição-aprendizagem, é comum a aceitação de uma das duas assertivas: "criança com fome não aprende" ou "a criança aprende mesmo com fome". Investigações na área da saúde e educação, a respeito da nutrição/desnutrição e sua relação com o aprender, evidenciam que a resposta não é tão simplista e que há um espectro muito mais amplo de relações causais entre nutrição/aprendizagem.

Considerando a situação do ensinar/aprender, a qual passa pela desvalorização da escola pública e o seu abandono pelo poder público, aponta-se que desde 1950 há um desmonte da escola, com diminuição das verbas, defasagem do salário dos professores, descuido na sua formação e, ao mesmo tempo, aumento do número de matrículas em todos os níveis de ensino. Permanecem altas e sempre inalteradas as taxas de evasão e repetência, apesar da ampliação do acesso à escolaridade, e continuam baixos os índices de terminalidade escolar, em todos os níveis. Por outro lado, sabe-se que um contingente de crianças e adolescentes só consegue estudar se estiver trabalhando, já que as condições de vida e de sobrevivência da família exigem inserção precoce na força de trabalho. $O$ ensino noturno, período muito frequientado na escola pública, apresenta matrícula elevada tanto no primeiro como no segundo graus, exigindo estudos que definam e esclareçam a questão ensino/aprendizagem quando o aluno já trabalha e as condições de formação do professor para atender a esses alunos trabalhadores ${ }^{6}$.

6. CARVALHO, Célia P. O difícil acesso à escola primária pública. São Paulo: 1945-64. São Paulo: UNICAMP, 1988. (Tese de Doutorado) 
Outra questão importante ligada à Educação Ambiental e que é freqüentemente ideologizada refere-se à relação criança/ensino de Ciências. $\mathrm{O}$ professor de Ciências, geralmente um biólogo, não tem o preparo necessário para, sozinho, dar conta de ciências (física, química, geociências, biologia). Por outro lado, o ensino de Ciências da primeira à quarta séries do primeiro grau fica sob responsabilidade de um único professor e há necessidade de atividades como visitas programadas de escolas/alunos/professores a laboratórios de ensino, a núcleos de ensino e entrosamento em grupos de estudo no contexto da formação continuada de professores 7 .

Organizar bibliografia, grupos de estudos, provocar programas são procedimentos não dissociados da sistematização dos dados, da avaliação da rotina, da verificação de literatura etc.

Imprimir a característica de investigação à trajetória não significa estar tendendo ao academicismo, mas à sistematização do trabalho que tem ficado em nível do senso comum, marcado por um "fazer sem fim", recomeçando a cada término do seu contrato. $O$ professor faz a escola, mas esta não tem a memória do seu trabalho.

$\mathrm{Na}$ tentativa de estabelecer um programa de Educação Ambiental que contemple a produção de conhecimentos sobre o assunto, a socialização do conhecimento que permita o desenvolvimento de tecnologias possíveis de serem repassadas a empresas e órgãos governamentais, e também de respaldarem a "militância ecológica" de grupos que pretendam a formação de uma "consciência ecoló- gica" entre os cidadãos, exige-se um novo paradigma científico que modifique o modo de produção do conhecimento.

Produção que não seja mais resultado de um trabalho individual, isolado, mas o produto de um trabalho coletivo, que incorporou os problemas básicos, fundamentais da própria construção/socialização do conhecimento ${ }^{8}$.

\section{PRÁTICAS DE SAÚDE E DE EDUCAÇÃO}

No processo de produzir conhecimentos que definam os contornos da Educação Ambiental e que ao mesmo tempo instaurem essa educação, está se constituindo, no campus da USP, o Núcleo de Estudos da Criança e do Adolescente, que tem entre seus propósitos questões em estreita relação com o meio ambiente. Entre elas se destacam: a educação escolar e nela o acesso e permanência; a diversidade e a distribuição ecológica das escolas; a formação continuada dos professores; a relação saúde/aprendizagem; o processo de crescimento da criança e do adolescente e a compreensão desse processo. Busca-se o encontro entre as instituições formadoras de profissionais de saúde e de educação, que são também produtoras de conhecimento, com as instituições nas quais se dão as chamadas práticas de saúde e as práticas educacionais. Essas questões se interligam, ainda que de forma desarticulada, porque apontam para um problema básico que é a formação do profissional da saúde e da educação, os quais lidam

7. BARBIERI, Marisa Ramos. O ensino de Ciências no $1^{\circ}$ grau. ln: TOZZI, D. A. et al. A didática e a Escola de $1^{\circ}$ grau. São Paulo: FDE, 1991, 11:129-40. Série IDÉlAS.

8. BARBIERI, Marisa Ramos et al. op. cit. p.143-6. 
com o mesmo sujeito/objeto que buscam esses serviços. Nessa trajetória do Núcleo está embutida a intencionalidade de melhoria da qualidade do serviço público de Educação e Saúde.

A característica mais marcante do projeto do Núcleo é o trânsito entre a orientação educacional da equipe permanente do LEC Laboratório de Ensino de Ciências -, a assessoria dos especialistas nas áreas específicas do conhecimento e as necessidades da Escola. O seu objetivo é o de trabalhar juntamente na organização, execução, registro e

Resumo: Os autores discutem as necessárias inter-relaçōes de saúde e educação que devem ser feitas quando se trata de tomar atitudes em relação ao Meio Ambiente. Entendem que tais relações devem extrapolar as abordagens unicamente biológicas e alcançar a dimensão social, econômica e política que o momento exige.

Palavras-chave: Meio Ambiente, saúde, educação, LEC - Laboratório de Ensino de Ciências. avaliação de programas que tenham como finalidade a criança e o adolescente.

Endereço para correspondência:

Profa. Dra. Marisa Ramos Barbieri

USP - Faculdade de Filosofia, Letras e Ciências Humanas

DPE - Laboratório de Ensino de Ciências

Av. Bandeirantes, 3900 Campus de Ribeirão

Preto

14040-901 Ribeirão Preto, SP

Telefone: $016-6331010$ ramais $384 / 212$ Fax: 016-6335015

Abstract: The authors discuss the necessary interrelation between health and education whenever attitudes concerning the environment must be taken. They believe that such relations must surpass the approaches essentially biologicals and reach the social, economic and political magnitude required nowadays.

Key-words: environment, health, education, LEC - Science Teaching Laboratory. 